\title{
REVIEW
}

Open Access

\section{Epidemiology of the association between serum 25-hydroxyvitamin D levels and musculoskeletal conditions among elderly individuals: a literature review}

Kazuhiko Arima', Satoshi Mizukami ${ }^{1}$, Takayuki Nishimura ${ }^{2}$, Yoshihito Tomita ${ }^{3}$, Hiroki Nakashima ${ }^{1}$, Yasuyo Abe ${ }^{1}$ and Kiyoshi Aoyagi ${ }^{1 *}$ (D)

\begin{abstract}
Background: Vitamin D deficiency is associated with osteoporosis, fracture, muscle weakness, falls, and osteoarthritis in adults. Elderly individuals are more likely to present with poor musculoskeletal conditions. Recently, several epidemiological studies have assessed the correlation between serum 25-hydroxyvitamin $\mathrm{D}(25(\mathrm{OH}) \mathrm{D})$ levels and musculoskeletal conditions in elderly individuals.

Main text: Osteoporosis is a skeletal disease characterized by low bone mass and microarchitectural deterioration of bone tissue, with a consequent increase in bone fragility and susceptibility to fracture. Numerous studies have shown a positive association between serum 25(OH)D levels and bone mineral density. Only a few studies have reported an association between serum $25(\mathrm{OH}) \mathrm{D}$ levels and quantitative ultrasound (QUS) parameters. Low serum 25(OH)D level may be a risk factor for hip fracture. However, data on the association between vitamin D deficiency and the incidence of non-hip fracture are contrasting. Falls are a major cause of mortality and morbidity in older adults. Several prospective population-based cohort studies have shown that low 25(OH)D levels are associated with an increased risk of falls. Reduced muscle strength and physical performance are risk factors for adverse events, including disability, institutionalization, and mortality. The role of vitamin D in musculoskeletal functionality (muscle weakness and physical performance) among elderly individuals is still controversial. Osteoarthritis (OA) is the most common form of arthritis and is a leading cause of disability among older adults. Data on the association between serum 25(OH)D levels and OA are contrasting.

Conclusion: Some studies have shown that vitamin D deficiency may be a risk factor for poor musculoskeletal conditions, such as osteoporosis, fracture, muscle weakness, falls, and osteoarthritis in adults. However, other studies did not find an association between serum 25(OH)D levels and musculoskeletal conditions.
\end{abstract}

\footnotetext{
* Correspondence: kiyoshi@nagasaki-u.ac.jp

'Department of Public Health, Nagasaki University Graduate School of Biomedical Sciences, Nagasaki, Japan

Full list of author information is available at the end of the article
}

(c) The Author(s). 2020 Open Access This article is licensed under a Creative Commons Attribution 4.0 International License, which permits use, sharing, adaptation, distribution and reproduction in any medium or format, as long as you give appropriate credit to the original author(s) and the source, provide a link to the Creative Commons licence, and indicate if changes were made. The images or other third party material in this article are included in the article's Creative Commons licence, unless indicated otherwise in a credit line to the material. If material is not included in the article's Creative Commons licence and your intended use is not permitted by statutory regulation or exceeds the permitted use, you will need to obtain permission directly from the copyright holder. To view a copy of this licence, visit http://creativecommons.org/licenses/by/4.0/ The Creative Commons Public Domain Dedication waiver (http://creativecommons.org/publicdomain/zero/1.0/) applies to the data made available in this article, unless otherwise stated in a credit line to the data. 


\section{Introduction}

Vitamin D is produced in the skin via exposure to ultraviolet (UV) light or intake of food. Then, it is hydroxylated by the liver to 25-hydroxyvitamin D (25(OH)D), which is the primary circulating form, and further hydroxylated by the kidney to 1,25-dihydroxyvitamin $\mathrm{D}(1$, $\left.25(\mathrm{OH})_{2} \mathrm{D}\right)$, which is the active form [1]. Thus, environment (exposure to UV radiation from the sun) and nutrition (intake of vitamin D-rich food or supplements) contribute to vitamin $\mathrm{D}$ production.

Vitamin D deficiency is associated with osteoporosis, fracture, muscle weakness, falls, or osteoarthritis in adults [2]. Elderly individuals are more likely to present with poor musculoskeletal conditions. Fractures lead to considerable disability and premature death among elderly individuals [3]. With increased life expectancy, elderly people comprise a high portion of the community. Deterioration of musculoskeletal health is a serious problem among elderly individuals.

Understanding the relationship among environment, nutrition, and physical (musculoskeletal) conditions is important in physiological anthropology [4-7]. Recently, several epidemiological studies have evaluated the correlation between serum 25(OH)D levels and musculoskeletal conditions among elderly individuals. However, the associations between serum 25(OH)D levels and musculoskeletal conditions remain controversial since previous studies have shown conflicting results. The current study aimed to review the epidemiological topic of serum $25(\mathrm{OH}) \mathrm{D}$ levels and its musculoskeletal impacts.

\section{Osteoporosis}

Osteoporosis is a skeletal disease characterized by low bone mass and microarchitectural deterioration of bone tissue with a consequent increase in bone fragility and susceptibility to fracture [8].

\section{Bone mass: bone mineral density (BMD) and quantitative ultrasound (QUS) parameters}

The measurement of bone mass (BMD) is the most straightforward approach for the diagnosis of osteoporosis [9]. Several studies have shown a positive association between serum 25(OH)D levels and BMD.

Bischoff-Ferrari et al. [10] showed a significant positive association between serum 25(OH)D levels and total hip BMD in older white, Mexican American, and black adults in the USA. Nakamura et al. [11] have found that higher serum 25(OH)D concentrations are associated with increased femoral neck BMD in home-dwelling postmenopausal Japanese women. Moreover, a serum $25(\mathrm{OH}) \mathrm{D}$ concentration of at least $70 \mathrm{nmol} / \mathrm{L}$ is required to achieve a high femoral neck BMD, and at least 50 $\mathrm{nmol} / \mathrm{L}$ is needed to achieve normal parathyroid hormone levels and to prevent low BMD. Mezquita-Raya et al. [12] have found that lumbar spine BMD is significantly associated with 25(OH)D levels in 161 healthy postmenopausal women. Malavolta et al. [13] have revealed a significant positive correlation between spine and hip BMD and 25(OH)D levels in 156 Italian postmenopausal women. Yamauchi et al. [14] showed that BMD was significantly correlated with $25(\mathrm{OH}) \mathrm{D}$ levels after adjusting for age, body mass index, and serum creatinine and parathyroid hormone levels in 202 Japanese postmenopausal women. Liu et al. [15] assessed 4595 participants (2281 men and 2314 women) aged $\geq 50$ years who participated in the National Health and Nutrition Examination Survey 2001-2006. Results showed that serum 25(OH)D levels were positively correlated with lumbar BMD in older adults.

The QUS of the bone is an ionizing radiation-free and relatively inexpensive, portable screening technique for osteoporosis and/or fracture risk assessment [16]. A few studies have reported an association between serum 25(OH)D levels and QUS parameters [17, 18]. Two studies found a positive association between serum 25(OH)D levels and speed of sound (SOS) [17, 18]. However, only one study revealed a positive association between serum $25(\mathrm{OH}) \mathrm{D}$ levels and broadband ultrasound attenuation (BUA) [17].

Kauppi et al. [17] investigated 2736 men and 3299 women aged $\geq 30$ years from a nationally representative population sample in Finland. Results showed that serum $25(\mathrm{OH}) \mathrm{D}$ level is an independent determinant of BUA ( $p<0.0001$ for men, $p<0.001$ for women) and SOS ( $p<0.0001$ for men, $p<0.05$ for women). Grigoriou et al. [18] investigated 970 adults recruited from rural and urban areas in Greece. Results showed that individuals with $25(\mathrm{OH}) \mathrm{D}$ levels $\geq 20 \mathrm{ng} / \mathrm{mL}$ had a higher SOS than those with $25(\mathrm{OH}) \mathrm{D}$ levels $<20 \mathrm{ng} / \mathrm{mL}$.

\section{Hip and other types of fracture}

Fragility fractures commonly occur among patients with osteoporosis, and they are considered an important public health issue. Low serum $25(\mathrm{OH}) \mathrm{D}$ level was found to be a risk factor for hip fracture [19-21].

Looker and Mussolino [19] investigated 1917 white men and women aged $\geq 65$ years who participated in the third National Health and Nutrition Examination Survey 1988-1994. They found that serum 25(OH)D level was correlated with a significantly lower risk of hip fracture after adjusting for several relevant confounding variables. Robinson-Cohen et al. [20] assessed 2294 ambulatory older adults (mean age 74 years) in a study with a median follow-up of 13 years. Results showed that serum $25(\mathrm{OH}) \mathrm{D}$ concentrations were associated with the risk of long-term hip fracture. Steingrimsdottir et al. [21] evaluated 5764 men and women aged 66-96 years in a study with a mean follow-up period of 5.4 years. They showed 
that compared with a reference value of $50-75 \mathrm{nmol} / \mathrm{L}$, the hazard ratios for hip fractures were 2.24 (95\% confidence interval $[\mathrm{CI}] 1.63,3.09)$ for serum 25(OH)D levels $<30 \mathrm{nmol} / \mathrm{L}$ after adjusting for age, sex, body mass index, height, smoking, alcohol intake and season, and 2.08 (95\% CI 1.51, 2.87) after adjusting additionally for physical activity.

Data on the association between vitamin D deficiency and the incidence of non-hip fracture are contrasting.

Some studies have reported an association between vitamin D deficiency and the risk of non-hip fracture [22-25]. Bleicher et al. [22] investigated a cohort of 1662 community-dwelling men aged 70-97 years in a study with a mean follow-up period of 4.3 years. They found that the risk of fracture was highest in men with $25(\mathrm{OH}) \mathrm{D}$ levels in the lowest quintile $(25(\mathrm{OH}) \mathrm{D}$ level $\leq 36 \mathrm{nmol} / \mathrm{L}$; hazard ratio $[\mathrm{HR}]=3.5 ; 95 \% \mathrm{CI} 1.7-7.0)$ and in men with $25(\mathrm{OH}) \mathrm{D}$ levels in the highest quintile $(25(\mathrm{OH}) \mathrm{D}$ level $>72 \mathrm{nmol} / \mathrm{L}$; $\mathrm{HR}=2.7$; 95\% CI 1.4-5.4) compared with men with $25(\mathrm{OH}) \mathrm{D}$ levels in the 4th quintile $(25(\mathrm{OH}) \mathrm{D}$ level $\geq 60$ to $\leq 72 \mathrm{nmol} / \mathrm{L}$ ). This result indicated that extremely high or low serum 25(OH)D levels may have negative effects on fracture risk. Tanaka et al. [23] investigated 1470 postmenopausal Japanese women in a study with a mean follow-up period of 7.2 years. They found that $25(\mathrm{OH}) \mathrm{D}$ level was a leading risk factor for long bone fractures. Nakamura et al. [24] conducted a cohort study with a 6-year follow-up on 773 community-dwelling women aged $\geq 69$ years old. Results showed that a sufficient vitamin D status (serum $25(\mathrm{OH}) \mathrm{D}$ levels $\geq 71 \mathrm{nmol} / \mathrm{L}$ ) was associated with low limb and vertebral fracture risk. Van Schoor et al. [25] conducted a 6-year follow-up study on 1311 community-dwelling older men and women from the Longitudinal Aging Study Amsterdam. They found that serum 25(OH)D levels $\leq 12$ $\mathrm{ng} / \mathrm{mL}$ were associated with an increased risk of fracture in individuals aged $65-75$ years.

Other studies did not reveal any associations between low serum $25(\mathrm{OH}) \mathrm{D}$ levels and a higher risk of fracture [26, 27]. Garnero et al. [26] investigated 669 postmenopausal women (mean age 62.2 years) in a prospective study with a mean follow-up period of 11.2 years. Results showed that after adjusting for age, there was no significant difference in incidence of fracture between women with $25(\mathrm{OH}) \mathrm{D}$ levels below or above 75,50 , or $30 \mathrm{nmol} / \mathrm{L}$. Chan et al. [27] investigated 712 men aged $\geq 65$ years in a 4-year follow-up study. They found no association between serum 25(OH)D levels and risk of non-vertebral fracture or hip fracture after adjusting for confounding factors.

\section{Falls}

Falls are one of the major causes of mortality and morbidity in older adults $[28,29]$. The ability of balance and gait control, and musculoskeletal functions are important risk factors for falls $[28,30]$.
In a cross-sectional study, Suzuki et al. [31] assessed 2957 Japanese community-dwelling elderly individuals (950 men and 2007 women) aged 65-92 years. Results showed that low 25(OH)D levels were significantly associated with a high prevalence of falls in elderly Japanese women.

Several prospective population-based cohort studies have shown that low $25(\mathrm{OH}) \mathrm{D}$ levels are associated with an increased risk of falls [32-34]. Rothenbacher et al. [32] evaluated 1385 participants aged $\geq 65$ years (mean age 75.6 years) in a 1-year follow-up study. They showed an association between serum $25(\mathrm{OH}) \mathrm{D}$ levels and risk of first fall, which was evident in participants with serum calcium levels within the upper normal limit, independent of renal function. Shimizu et al. [33] investigated community-dwelling elderly women aged $\geq 75$ years $(n=$ 1393) in a 1-year follow-up study. They found that a lower serum $25(\mathrm{OH}) \mathrm{D}$ level $(<20 \mathrm{ng} / \mathrm{mL})$ was significantly associated with an increased risk of falls. Machado et al. [34] evaluated 705 community-dwelling elderly individuals (448 women, 257 men) in a study with a mean follow-up period of $4.3 \pm 0.8$ years. They found that hypovitaminosis $\mathrm{D}$ was associated with recurrent falls.

\section{Muscle weakness and physical performance}

Reduced muscle strength and physical performance are risk factors for adverse events, including disability, institutionalization, and mortality [35]. The role of vitamin $\mathrm{D}$ in musculoskeletal functionality (muscle weakness and physical performance) among elderly individuals remains controversial.

Some studies have shown an association between vitamin D deficiency and muscle weakness or poor physical performance [36-39]. Bischoff-Ferrari et al. [36] found that in both active and inactive ambulatory persons aged $\geq 60$ years, $25(\mathrm{OH}) \mathrm{D}$ levels between 40 and $94 \mathrm{nmol} / \mathrm{L}$ are associated with better musculoskeletal function in the lower extremities than are levels $<40 \mathrm{nmol} / \mathrm{L}$. Houston et al. [37] conducted a study on 976 individuals aged $\geq 65$ years. Results showed that vitamin D levels were significantly associated with Short Physical Performance Battery (SPPB) (walking speed, ability to stand from a chair, and ability to maintain balance in progressively more challenging positions [side-by-side position, semitandem position, and full-tandem position]) in men ( $p=$ $0.04)$ and handgrip strength in men $(p=0.004)$ and women $(p=0.01)$. Aspell et al. [38] evaluated for handgrip strength and SPPB in 4157 community-dwelling adults with a mean age of $69.8 \pm 6.9$ years. Their study showed that vitamin D deficiency $(<30 \mathrm{nmol} / \mathrm{L})$ was a significant determinant of low handgrip strength (odds ratio $[\mathrm{OR}] 1.44[1.22,1.71], p<0.001)$ and poor physical performance (OR 1.65 [1.31, 2.09], $p<0.001$ ). Toffanello et al. [39] found that lower $25(\mathrm{OH}) \mathrm{D}$ levels were 
associated with worse coordination and weaker strength (5 timed chair stands) in women, slower walking time, and lower upper limb (handgrip) strength in men and a weaker aerobic capacity (6-min walking) in both genders in 2694 community-dwelling elderly women and men from the Progetto Veneto Anziani study.

Other studies did not show any associations between vitamin D deficiency and muscle weakness or poor physical performance [40-42]. Vaes et al. [40] investigated 756 men and women aged $\geq 65$ years. Their study showed that serum $25(\mathrm{OH}) \mathrm{D}$ concentrations were significantly associated with frailty status and measures of physical performance, including gait speed and the Timed Up and Go test, but not with strength-related outcomes (handgrip strength or knee-extension strength). Annweiler et al. [41] evaluated the maximal isometric voluntary contraction strength of the lower limb and hand with computerized dynamometers in a randomized sample of 440 women included in the EPIDOS study. Results showed that the mean muscle strength did not differ among the three groups of women (serum 25(OH)D levels < $15 \mathrm{ng} / \mathrm{mL}, 15-30 \mathrm{ng} /$ $\mathrm{mL}$, and $>30 \mathrm{ng} / \mathrm{mL}$ with $p=0.946$ for the quadriceps and $p=0.064$ for handgrip). This result does not support the hypothesis stating that a relationship exists between low serum 25(OH)D concentrations and low muscle strength. Mathei et al. [42] found no significant relationship between balance, gait speed, and grip strength as well as serum 25(OH)D levels in 367 individuals aged $\geq 80$ years.

\section{Osteoarthritis}

Osteoarthritis (OA) is the most common form of arthritis, affecting approximately 302 million people worldwide. Moreover, it is a leading cause of disability among older adults [43]. Data on the association between serum 25(OH)D levels and OA are contrasting.

Several studies showed the association between serum 25(OH)D level and OA [44-46]. In a cross-sectional study, Veronese et al. [44] found that low 25(OH)D levels were associated with the presence of $\mathrm{OA}$ and with OA-related pain, particularly when the hand and hip are involved in 2756 subjects (1102 men and 1654 women) with a mean age of $74.2 \pm 7.1$ years. Heidari et al. [45] investigated 148 patients with knee OA and 150 controls and found a significant association between serum $25(\mathrm{OH}) \mathrm{D}$ deficiency and knee $\mathrm{OA}$ in patients aged $<60$ years. Zhang et al. [46] evaluated 418 participants who had $\geq 1$ knee with both symptomatic and radiographic OA prospectively (between the 24 and 48 months). Results showed that participants with low 25(OH)D levels $(<15 \mu \mathrm{g} / \mathrm{L})$ had a $>2$-fold elevated risk of knee OA progression compared with those with greater vitamin $\mathrm{D}$ concentrations $(\geq 15 \mu \mathrm{g} / \mathrm{L})$.
However, other studies did not show an association between low 25(OH)D levels and a higher risk of knee OA $[47,48]$. In a cross-sectional study, Muraki et al. [47] found that $25(\mathrm{OH}) \mathrm{D}$ levels were not significantly associated with radiographic knee OA in 787 participants in the Hertfordshire Cohort Study (399 men, 388 women; mean age of $65.6 \pm 2.7$ years). Konstari et al. [48] conducted a cohort study comprising 5274 Finns who participated in a national health examination survey and who had no knee or hip OA at baseline and at the 10-year follow-up. Results showed that a low serum $25(\mathrm{OH}) \mathrm{D}$ concentration was not effective in predicting the high incidence of knee and hip OA.

\section{Conclusion}

Some studies showed that vitamin D deficiency may be a risk factor for poor musculoskeletal conditions, such as osteoporosis, fracture, muscle weakness, falls, and osteoarthritis in adults. However, other studies did not show an association between serum 25(OH)D levels and musculoskeletal conditions. Thus, the associations between serum 25(OH)D levels and musculoskeletal conditions were conflicting. Further epidemiological studies should be conducted to explore the association between serum 25(OH)D levels and musculoskeletal conditions. In addition, a systematic review and meta-analysis of randomized trials showed the small benefit of vitamin D supplements at the femoral neck bone mineral density, but not at any other site [49]. Intervention studies on vitamin D supplementation would be needed to clarify the effect of vitamin D on musculoskeletal conditions and its optimal serum levels to maintain a good physical function, thereby improving the health management of elderly individuals.

\section{Abbreviations}

UV: Ultraviolet; 25(OH)D: 25-Hydroxyvitamin D; 1,25(OH)2D: 1,25Dihydroxyvitamin D; BMD: Bone mineral density; QUS: Quantitative

ultrasound; SOS: Speed of sound; BUA: Broadband ultrasound attenuation; SPPB: Short physical performance battery; OA: Osteoarthritis

\section{Acknowledgements}

Not applicable.

\section{Authors' contributions}

KA and KA participated in the design of the study; KA, SM, and HN searched the literature; TN and YT selected the reviewed articles; and KA and YA wrote the draft of the manuscript. All authors approved the final version of the manuscript.

\section{Funding}

This work was supported by Grants-in-Aid for Scientific Research (KAKENHI No. JP 19H03317) from the Japan Society for the Promotion of Science.

Availability of data and materials Not applicable.

Ethics approval and consent to participate Not applicable. 


\section{Consent for publication}

Not applicable.

\section{Competing interests}

The authors declare that they have no competing interests.

\section{Author details}

'Department of Public Health, Nagasaki University Graduate School of Biomedical Sciences, Nagasaki, Japan. ${ }^{2}$ Department of Human Science, Faculty of Design, Kyushu University, Fukuoka, Japan. ${ }^{3}$ School of Rehabilitation, Department of Physical Therapy, Tokyo Professional University of Health Sciences, Tokyo, Japan.

Received: 7 August 2020 Accepted: 18 November 2020

\section{Published online: 26 November 2020}

\section{References}

1. Lips P. Vitamin D deficiency and secondary hyperparathyroidism in the elderly: consequences for bone loss and fractures and therapeutic implications. Endocr Rev. 2001;22 4:477-501.

2. Holick MF. Vitamin D deficiency. N Engl J Med. 2007:357 3:266-281.

3. Cummings SR, Kelsey JL, Nevitt MC, O'Dowd KJ. Epidemiology of osteoporosis and osteoporotic fractures. Epidemiol Rev. 1985;7:178-208.

4. Hasegawa J, Suzuki H, Yamauchi T. Impact of season on the association between muscle strength/volume and physical activity among communitydwelling elderly people living in snowy-cold regions. J Physiol Anthropol. 2018:37 1:25.

5. Huang L, Ye Z, Lu J, Kong C, Zhu Q, Huang B, et al. Effects of fat distribution on lung function in young adults. J Physiol Anthropol. 2019:38 1:7.

6. Tanaka N, Arima K, Nishimura T, Tomita Y, Mizukami S, Okabe T, et al. Vitamin $\mathrm{K}$ deficiency, evaluated with higher serum ucOC, was correlated with poor bone status in women. J Physiol Anthropol. 2020;39 1:9.

7. Numao S, Katayama Y, Nakata Y, Matsuo T, Nakagaichi M, Tanaka K. Association of abdominal fat with metabolic syndrome components in overweight women: effect of menopausal status. J Physiol Anthropol. 2020; $391: 12$

8. Consensus development conference: diagnosis, prophylaxis, and treatment of osteoporosis. Am J Med. 1993;94 6:646-50.

9. WorldHealthOrganizationStudyGroup: Assessment of fracture risk and its application to screening for postmenopausal osteoporosis. In: WHO technical report series. Geneva; 1994.

10. Bischoff-Ferrari HA, Dietrich T, Orav EJ, Dawson-Hughes B. Positive association between 25-hydroxy vitamin $\mathrm{D}$ levels and bone mineral density: a population-based study of younger and older adults. Am J Med. 2004; 116(9):634-9.

11. Nakamura K, Tsugawa N, Saito T, Ishikawa M, Tsuchiya Y, Hyodo K, et al. Vitamin D status, bone mass, and bone metabolism in home-dwelling postmenopausal Japanese women: Yokogoshi Study. Bone. 2008;42(2):2717.

12. Mezquita-Raya P, Munoz-Torres M, Luna JD, Luna V, Lopez-Rodriguez F,

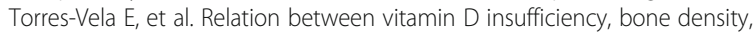
and bone metabolism in healthy postmenopausal women. J Bone Miner Res. 2001;16(8):1408-15.

13. Malavolta N, Pratelli L, Frigato M, Mule R, Mascia ML, Gnudi S. The relationship of vitamin $\mathrm{D}$ status to bone mineral density in an Italian population of postmenopausal women. Osteoporos Int. 2005;16(12):1691-7.

14. Yamauchi M, Kaji H, Nawata K, Takaoka S, Yamaguchi T, Sugimoto T. Role of parathyroid hormone in bone fragility of postmenopausal women with vitamin D insufficiency. Calcif Tissue Int. 2011;88(5):362-9.

15. Liu M, Yao X, Zhu Z. Associations between serum calcium, 25(OH)D level and bone mineral density in older adults. J Orthop Surg Res. 2019;14 1:458.

16. Krieg MA, Cornuz J, Ruffieux C, Van Melle G, Buche D, Dambacher MA, et al. Prediction of hip fracture risk by quantitative ultrasound in more than 7000 Swiss women $>$ or $=70$ years of age: comparison of three technologically different bone ultrasound devices in the SEMOF study. J Bone Miner Res. 2006;21(9):1457-63.

17. Kauppi M, Impivaara O, Maki J, Heliovaara M, Marniemi J, Montonen J, et al. Vitamin D status and common risk factors for bone fragility as determinants of quantitative ultrasound variables in a nationally representative population sample. Bone. 2009;45(1):119-24.
18. Grigoriou EV, Trovas G, Papaioannou N, Makras P, Kokkoris P, Dontas I, et al. Serum 25-hydroxyvitamin D status, quantitative ultrasound parameters, and their determinants in Greek population. Arch Osteoporos. 2018;13 1:111.

19. Looker AC, Mussolino ME. Serum 25-hydroxyvitamin D and hip fracture risk in older U.S. white adults. J Bone Miner Res. 2008;23 1:143-50.

20. Robinson-Cohen C, Katz R, Hoofnagle AN, Cauley JA, Furberg CD, Robbins $J A$, et al. Mineral metabolism markers and the long-term risk of hip fracture: the cardiovascular health study. J Clin Endocrinol Metab. 2011;96(7):218693.

21. Steingrimsdottir $L$, Halldorsson $T$, Siggeirsdottir K, Cotch MF, Einarsdottir BO, Eiriksdottir $\mathrm{G}$, et al. Hip fractures and bone mineral density in the elderly-importance of serum 25-hydroxyvitamin D. PLoS One. 2014;9 3:e91122.

22. Bleicher K, Cumming RG, Naganathan V, Blyth FM, Le Couteur DG, Handelsman DJ, et al. U-shaped association between serum 25hydroxyvitamin $D$ and fracture risk in older men: results from the prospective population-based CHAMP study. J Bone Miner Res. 2014;29(9): 2024-31.

23. Tanaka S, Kuroda T, Yamazaki Y, Shiraki Y, Yoshimura N, Shiraki M. Serum 25hydroxyvitamin D below $25 \mathrm{ng} / \mathrm{mL}$ is a risk factor for long bone fracture comparable to bone mineral density in Japanese postmenopausal women. J Bone Miner Metab. 2014;32(5):514-23.

24. Nakamura K, Saito T, Oyama M, Oshiki R, Kobayashi R, Nishiwaki T, et al. Vitamin D sufficiency is associated with low incidence of limb and vertebral fractures in community-dwelling elderly Japanese women: the Muramatsu Study. Osteoporos Int. 2011;22(1):97-103.

25. van Schoor NM, Visser M, Pluijm SM, Kuchuk N, Smit JH, Lips P. Vitamin D deficiency as a risk factor for osteoporotic fractures. Bone. 2008;42(2):260-6.

26. Garnero P, Munoz F, Sornay-Rendu E, Delmas PD. Associations of vitamin D status with bone mineral density, bone turnover, bone loss and fracture risk in healthy postmenopausal women. The OFELY study. Bone. 2007:40 3:716-22.

27. Chan R, Chan CC, Woo J, Ohlsson C, Mellstrom D, Kwok T, et al. Serum 25hydroxyvitamin $\mathrm{D}$, bone mineral density, and non-vertebral fracture risk in community-dwelling older men: results from Mr. Os, Hong Kong. Arch Osteoporos. 2011;6:21-30.

28. Ambrose AF, Paul G, Hausdorff JM. Risk factors for falls among older adults: a review of the literature. Maturitas. 2013;75(1):51-61.

29. Mizukami S, Arima K, Abe Y, Kanagae M, Kusano Y, Niino N, et al. Falls are associated with stroke, arthritis and multiple medications among community-dwelling elderly persons in Japan. Tohoku J Exp Med. 2013; 231(4):299-303

30. Saftari LN, Kwon OS. Ageing vision and falls: a review. J Physiol Anthropol. 2018:37 1:11

31. Suzuki T, Kwon J, Kim H, Shimada H, Yoshida Y, Iwasa H, et al. Low serum 25-hydroxyvitamin D levels associated with falls among Japanese community-dwelling elderly. J Bone Miner Res. 2008;23(8):1309-17.

32. Rothenbacher D, Klenk J, Denkinger MD, Herbolsheimer F, Nikolaus T, Peter $R$, et al. Prospective evaluation of renal function, serum vitamin $D$ level, and risk of fall and fracture in community-dwelling elderly subjects. Osteoporos Int. 2014;25(3):923-32.

33. Shimizu Y, Kim H, Yoshida H, Shimada H, Suzuki T. Serum 25-hydroxyvitamin $\mathrm{D}$ level and risk of falls in Japanese community-dwelling elderly women: a 1-year follow-up study. Osteoporos Int. 2015;26(8):2185-92.

34. Machado KL, Domiciano DS, Machado LG, Lopes JB, Figueiredo CP, Takayama L, et al. Persistent hypovitaminosis $D$ and loss of hip bone mineral density over time as additional risk factors for recurrent falls in a population-based prospective cohort of elderly persons living in the community. The Sao Paulo Ageing \& Health (SPAH) Study. Osteoporos Int 2015:26 5:1535-42

35. Remelli F, Vitali A, Zurlo A, Volpato S. Vitamin D deficiency and sarcopenia in older persons. Nutrients. 2019:11:12.

36. Bischoff-Ferrari HA, Dietrich T, Orav EJ, Hu FB, Zhang Y, Karlson EW, et al. Higher 25-hydroxyvitamin D concentrations are associated with better lower-extremity function in both active and inactive persons aged $>$ or $=60$ y. Am J Clin Nutr. 2004;80(3):752-8.

37. Houston DK, Cesari M, Ferrucci L, Cherubini A, Maggio D, Bartali B, et al. Association between vitamin D status and physical performance: the InCHIANTI study. J Gerontol A Biol Sci Med Sci. 2007;62(4):440-6.

38. Aspell N, Laird E, Healy M, Lawlor B, O'Sullivan M. Vitamin D deficiency is associated with impaired muscle strength and physical performance in community-dwelling older adults: findings from The English Longitudinal Study Of Ageing. Clin Interv Aging. 2019;14:1751-61. 
39. Toffanello ED, Perissinotto E, Sergi G, Zambon S, Musacchio E, Maggi S, et al. Vitamin $D$ and physical performance in elderly subjects: the Pro.V.A study. PLoS One. 2012;7 4:e34950.

40. Vaes AMM, Brouwer-Brolsma EM, Toussaint N, de Regt M, Tieland M, van Loon LC, et al. The association between 25-hydroxyvitamin D concentration, physical performance and frailty status in older adults. Eur J Nutr. 2019;58(3):1173-81.

41. Annweiler C, Beauchet O, Berrut G, Fantino B, Bonnefoy M, Herrmann FR, et al. Is there an association between serum 25-hydroxyvitamin $D$ concentration and muscle strength among older women? Results from baseline assessment of the EPIDOS study. J Nutr Health Aging. 2009;13(2): 90-5.

42. Mathei C, Van Pottelbergh G, Vaes B, Adriaensen W, Gruson D, Degryse JM. No relation between vitamin $D$ status and physical performance in the oldest old: results from the Belfrail study. Age Ageing. 2013:42(2):186-90

43. Kolasinski SL, Neogi T, Hochberg MC, Oatis C, Guyatt G, Block J, et al. 2019 American College of Rheumatology/Arthritis Foundation Guideline for the management of osteoarthritis of the hand, hip, and knee. Arthritis Rheumatol. 2020;72 2:220-233.

44. Veronese N, Maggi S, Noale M, De Rui M, Bolzetta F, Zambon S, et al. Serum 25-hydroxyvitamin D and osteoarthritis in older people: the Progetto Veneto Anziani study. Rejuvenation Res. 2015;18(6):543-53.

45. Heidari B, Heidari P, Hajian-Tilaki K. Association between serum vitamin D deficiency and knee osteoarthritis. Int Orthop. 2011:35(11):1627-31.

46. Zhang FF, Driban JB, Lo GH, Price LL, Booth S, Eaton CB, et al. Vitamin D deficiency is associated with progression of knee osteoarthritis. J Nutr. 2014; 144(12):2002-8.

47. Muraki S, Dennison E, Jameson K, Boucher BJ, Akune T, Yoshimura N, et al. Association of vitamin D status with knee pain and radiographic knee osteoarthritis. Osteoarthritis Cartilage. 2011;19(11):1301-6.

48. Konstari S, Kaila-Kangas L, Jaaskelainen T, Heliovaara M, Rissanen $H$, Marniemi J, et al. Serum 25-hydroxyvitamin D and the risk of knee and hip osteoarthritis leading to hospitalization: a cohort study of 5274 Finns. Rheumatology (Oxford). 2014;53(10):1778-82.

49. Reid IR, Bolland MJ, Grey A. Effects of vitamin D supplements on bone mineral density: a systematic review and meta-analysis. Lancet. 2014; 383(9912):146-55.

\section{Publisher's Note}

Springer Nature remains neutral with regard to jurisdictional claims in published maps and institutional affiliations.

Ready to submit your research? Choose BMC and benefit from:

- fast, convenient online submission

- thorough peer review by experienced researchers in your field

- rapid publication on acceptance

- support for research data, including large and complex data types

- gold Open Access which fosters wider collaboration and increased citations

- maximum visibility for your research: over $100 \mathrm{M}$ website views per year

At BMC, research is always in progress.

Learn more biomedcentral.com/submissions 